\title{
$D L C-1$, a candidate tumor suppressor gene, inhibits the proliferation, migration and tumorigenicity of human nasopharyngeal carcinoma cells
}

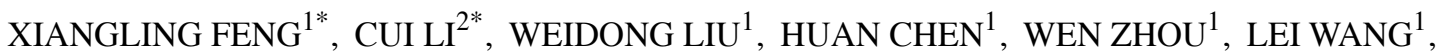 \\ BIN ZHU ${ }^{1}$, KAITAI YAO ${ }^{1,4}$, XINGJUN JIANG ${ }^{3}$ and CAIPING REN ${ }^{1}$
}

\begin{abstract}
${ }^{1}$ Cancer Research Institute, Xiang-Ya School of Medicine, Central South University, Key Laboratory for Carcinogenesis of Chinese Ministry of Health, Key Laboratory for Carcinogenesis and Cancer Invasion of Chinese Ministry of Education, Changsha, Hunan 410078; ${ }^{2}$ Key Laboratory of Cancer Proteomics of Chinese Ministry of Health, Xiangya Hospital, Central South University; ${ }^{3}$ Department of Neurosurgery, Xiangya Hospital, Central South University, Changsha, Hunan 410008; ${ }^{4}$ Cancer Institute, Southern Medical University, Guangzhou, Guangdong 510515, P.R. China
\end{abstract}

Received December 31, 2012; Accepted February 25, 2013

DOI: $10.3892 /$ ijo.2013.1885

\begin{abstract}
In our previous study we demonstrated the downregulation or loss of deleted in liver cancer-1 (DLC-1) gene expression in nasopharyngeal carcinoma (NPC). In this study, we report the effects of the $D L C-1$ gene on NPC cells and its mechanisms of action. $D L C-1$ expression was restored in the 5-8F NPC cell line, which lacks $D L C-1$ expression, and the biological characteristics of 5-8F-DLC-1 cells were analyzed by MTT assay, colony formation assay, flow cytometry (FCM), tumorigenesis analysis in nude mice, as well as invasion and migration assay. Differentially expressed genes in response to $D L C-1$ expression were screened using microarray analysis and identified by RT-PCR. The re-expression of DLC-1 in the NPC cells attenuated the proliferation and colony formation ability of the cells in vitro, blocked NPC cells at the G0/G1 phase, reduced tumorigenicity potential in vivo, inhibited the invasion and migration ability of NPC cells and resulted in the reorganization of the actin cytoskeleton. $D L C-1$ altered the gene expression profile in $5-8 \mathrm{~F}$ cells. Some tumor suppressor genes
\end{abstract}

Correspondence to: Professor Caiping Ren, Cancer Research Institute, Xiang-Ya School of Medicine, Central South University, Key Laboratory for Carcinogenesis of Chinese Ministry of Health, Key Laboratory for Carcinogenesis and Cancer Invasion of Chinese Ministry of Education, 110 Xiangya Road, Changsha, Hunan 410078, P.R. China

E-mail: rencaiping@csu.edu.cn

Professor Xingjun Jiang, Department of Neurosurgery, Xiangya Hospital, Central South University, 87 Xiangya Road, Changsha, Hunan 410008, P.R. China

E-mail: jiangxingjun@sina.com

*Contributed equally

Key words: nasopharyngeal carcinoma, deleted in liver cancer-1 gene, biological function, invasion, migration, microarray
(TSGs) were upregulated and some oncogenes were downregulated. These results demonstrate that $D L C-1$ gene can partially reverse the malignant phenotype of NPC cells by changing the tumor-related gene expression profile, and may be a candidate tumor suppressor gene and a promising diagnostic and therapeutic target in NPC.

\section{Introduction}

Nasopharyngeal carcinoma (NPC), an epithelial malignancy with high incidence in Southeast Asia and Southern China, is associated with genetic alteration and environmental factors (1-4). Although much progress has been made by studies on NPC, the exact molecular mechanisms underlying nasopharyngeal carcinogenesis remain unclear, and no significant breakthrough on the early detection and treatment of NPC has been achieved. It is widely considered that Epstein-Barr virus (EBV), chemical carcinogens and genetic susceptibility are three main factors involved in NPC pathogenesis. Previous studies have revealed numerous NPC-related genes, most of which are potential tumor suppressor genes (TSGs). However, these genes are only a small proportion of NPC-related genes and they are not sufficient to fully elucidate the molecular carcinogenesis of NPC (5).

Deleted in liver cancer-1 (DLC-1) gene, which was originally cloned by Yuan et al from liver tissue using representational difference analysis (RDA), is located at chromosome 8p22, and its full-length cDNA covers 6,044 bp (GeneBank ID: NM006094) (6). It encodes one of the Rho GTPase-activating proteins (GAPs), a negative regulator of the Rho family proteins by stimulating their intrinsic GTPase activity. $D L C-1$ is extensively expressed in normal tissues, but is downregulated or deleted in liver, gastric, lung and prostate cancer, as well as in multiple myeloma. Furthermore, it can significantly suppress proliferation and metastasis of many kinds of tumors $(7,8)$. Loss of heterozygosity $(\mathrm{LOH})$ and promoter hypermethylation are two of the main causes associated with the transcriptional silencing of $D L C-1$ in these tumors. Previously we and others have shown 
that $D L C-1$ is normally expressed in chronic nasopharyngitis tissues and normal nasopharyngeal epithelium, but is significantly downregulated or absent in NPC cell lines and tissues, and so it may play a critical role in carcinogenesis and the progression of NPC $(9,10)$. Promoter hypermethylation plays a key role in inactivating $D L C-1$ in NPC, although $\mathrm{LOH}$ is also involved in the aberrant expression of $D L C$ - 1 . In this study, we constructed a recombinant eukaryotic vector of $D L C-1$ and established a 5-8F cell line stably expressing high level of $D L C$-1. Furthermore, we investigated the function of $D L C-1$, as well as the effects of $D L C-1$ re-expression on the malignant phenotype and gene expression profile of NPC cells.

\section{Materials and methods}

Ethics statement. All animal experiments were performed according to the institutional guidelines approved by the Animal Care and Use Committee of Central South University, Changsha, China. We also received ethics approval from the Institutional Review Board of Central South University.

Cell culture. The NPC cell line, 5-8F, a subclone of SUNE-1 which was isolated from poorly differentiated squamous cell carcinoma tissue and exhibited high metastatic and tumorigenic ability, was preserved by our institute. It was cultured in RPMI-1640 supplemented with $10 \%$ newborn calf serum (NCS) at $37^{\circ} \mathrm{C}$ in a humidified $5 \% \mathrm{CO}_{2}$ atmosphere.

Plasmid construction, transfection and stable colony selection. RNA from human normal spleen tissue was reverse transcribed into cDNA with M-MLV reverse transcriptase (Promega, Madison, WI, USA). The entire open reading frame (ORF) fragment (approximately $3.3 \mathrm{~kb}$ ) of $D L C-1$ gene was amplified by RT-PCR with the cDNA as the template. The $D L C-1$ ORF forward and reverse amplification primers were 5'-GCCTGCCGTGCTTGATGTGC-3' and 5'-TGGTGGAA GCGGTTGCGTTG-3', respectively. The PCR product was TA-cloned into the pBS-T vector (Tiangen, Beijing, China) and sequenced. The entire $D L C-1$ ORF sequence was removed from pBS-T/DLC-1 following BamHI and KpnI digestion and was subcloned into pcDNA3.1(+) (Invitrogen, Carlsbad, CA, USA). The recombinant vector (pcDNA3.1/DLC-1) was transformed into DH5 a Escherichia coli and the plasmid DNA was isolated using the Miniprep kit (Qiagen, Hilden, Germany) for transfection.

The 5-8F cells were seeded into six-well plates with RPMI-1640 medium at a density of $3 \times 10^{5}$ cells/well. When reached $70-80 \%$ confluence, the cells were transfected with $2 \mu \mathrm{g}$ plasmid DNA (pcDNA3.1(+) or pcDNA3.1/DLC-1) using $8 \mu \mathrm{l}$ FuGENE 6 as described by the manufacturer (Roche, Basel, Switzerland). After $48 \mathrm{~h}$, the medium was replaced with fresh RPMI-1640 medium with $10 \%$ NCS and Geneticin (G418) in order to select clones stably harboring $D L C-1$ or the empty vector. The selected clones were named 5-8F-DLC-1 or $5-8 \mathrm{~F}-$ vector, respectively.

Western blot analysis and immunocytochemistry (ICC). Immunoblotting experiments and ICC analysis were performed according to the procedure outlined in our previous study (11). For each cell line, $2 \times 10^{6}$ cells were harvested and cell lysates were prepared using commercial cell lysis buffer (Pierce Biotechnology, Inc., Rockford, IL, USA) in western blot analysis. Equal amounts of protein $(30 \mu \mathrm{g})$ from whole cell lysates were separated by SDS-PAGE and transferred onto polyvinylidene fluoride (PVDF) membranes (Millipore, Billerica, MA, USA). The membranes were blocked with $5 \%$ non-fat milk in TBST buffer (1x Tris-buffered saline and $0.1 \%$ Tween-20) for $2 \mathrm{~h}$, and then incubated overnight at $4^{\circ} \mathrm{C}$ with mouse monoclonal anti-human DLC-1 antibody (1:300, BD Biosciences, Franklin Lakes, NJ, USA) and $\beta$-actin antibody (1:2000, Santa Cruz Biotechnology, Inc., Santa Cruz, CA, USA) which was used as a loading control. After washing with TBST buffer three times, the membranes were incubated with horseradish peroxidase-conjugated goat anti-mouse $\operatorname{IgG}$ antibody (1:2,000, Santa Cruz Biotechnology). Finally, the ECL western blotting detection system (Pierce Biotechnology, Inc.) and X-ray films were used to develop the blot images.

A 1:150 dilution of mouse monoclonal anti-human DLC-1 antibody was used in immunocytochemistry analysis. Briefly, cells seeded on slides were washed in PBS, fixed with $4 \%$ paraformaldehyde in PBS for $20 \mathrm{~min}$, and treated with $0.5 \%$ Triton X-100 in PBS (PBST) for $30 \mathrm{~min}$. Subsequently, endogenous peroxidase was inactivated by incubation in $3 \% \mathrm{H}_{2} \mathrm{O}_{2}$ in $\mathrm{dH}_{2} \mathrm{O}$ for $15 \mathrm{~min}$ at room temperature. After being rinsed with PBST, the cells were treated with $5 \%$ bovine serum albumin (BSA) in PBST ( $2 \mathrm{~h}$ at room temperature). DLC-1 antibody, the Histostain ${ }^{\mathrm{TM}}$-Plus kit (Zymed Laboratories Inc., South San Francisco, CA, USA) and the diaminobenzidine (DAB) substrate kit were then used to detect DLC-1 protein. Finally, the slides were lightly counterstained with hematoxylin, dehydrated, mounted with neutral balsam (Shanghai Specimen and Model Factory, Shanghai, China) and photographed under a microscope. For the negative control, the primary DLC-1 antibody was replaced with PBS.

MTT assay. MTT assay was performed as previously described (12). The 5-8F-DLC-1 and 5-8F-vector cells were seeded in 96-well plates at a density of $2 \times 10^{3}$ cells/well in $200 \mu \mathrm{l}$ culture medium (RPMI-1640 with serum). Three wells had no cells and were used as the control for the minimum absorbance. Cells were propagated at $37^{\circ} \mathrm{C}$ in an incubator with humidified $5 \% \mathrm{CO}_{2}$ atmosphere for one to seven days. The medium was discarded and the cells were incubated with $20 \mu \mathrm{l} /$ well MTT solution $(5 \mathrm{mg} / \mathrm{ml})$ for $4 \mathrm{~h}$ at $37^{\circ} \mathrm{C}$ followed by the addition of $150 \mu \mathrm{l} /$ well DMSO. Ten minutes later, the absorbance value was measured with an ELISA plate reader (ELx800, BioTek Instruments, Inc., Winooski, VT, USA) at a test wavelength of $490 \mathrm{~nm}$. The growth curves were drawn by EXCEL software.

Colony formation assay. The 5-8F-vector and 5-8F-DLC-1 cells were seeded in six-well plates at $1 \times 10^{3}$ cells/well and each cell line was seeded in triplicate. Cells were cultured in RPMI-1640 supplemented with $10 \%$ NCS at $37^{\circ} \mathrm{C}$ in a humidified $5 \% \mathrm{CO}_{2}$ atmosphere for eight days. After discarding the culture medium and washing with D-Hank's solution (three times), the cells were fixed with methanol for $15 \mathrm{~min}$ and stained with $0.4 \%$ crystal violet for $10-30 \mathrm{~min}$. After washing with water and drying in the air, clones containing $>50$ cells were counted under an inverse microscope (TE2000U; Nikon, Osaka, Japan). 
Flow cytometry $(F C M)$. As has been described in our previous study (11), the 5-8F-vector and 5-8F-DLC-1 cells $\left(1 \times 10^{6}\right.$ cells per sample) were collected and washed with $\mathrm{PBS}$, fixed in $70 \%$ ethanol and stored at $4^{\circ} \mathrm{C}$. All samples were resuspended in PBS containing RNase A (100 U/ml, Sigma, St. Louis, MO, USA) and incubated at $37^{\circ} \mathrm{C}$ for $30 \mathrm{~min}$, stained with propidium iodide (PI, $50 \mu \mathrm{g} / \mathrm{ml}$, Sigma), and analyzed by FCM (BD FACSCalibur ${ }^{\mathrm{TM}}$; BD Biosciences). The cell cycle distribution was calculated from the resultant DNA histogram using Mod Fit LT software.

In vivo tumorigenicity assay. A total of 12 (six male and six female) four to six-week-old BALB/c-nu/nu nude mice were purchased from Shanghai SLAC Laboratory Animal Co., Ltd. The 5-8F-DLC-1 and 5-8F-vector cells (5x10 6 cells/each type) were injected subcutaneously into the proximal dorsal midline of three four to six-week-old male nude mice and three four to six-week-old female nude mice. Tumor size was subsequently measured in two dimensions twice a week. All the mice were sacrificed 45 days after injection and were examined for the presence of tumors. Tumors were removed from the nude mice, measured and weighed for tumorigenicity analysis.

Wound healing assay. The 5-8F-vector and 5-8F-DLC-1 cells were seeded into six-well plates at a density of $1 \times 10^{6}$ cells/well. The following day, the confluent cell monolayer was wounded with a sterile $200 \mu \mathrm{l}$ tip and plates were returned to cell culture incubator. Images were captured at the beginning and after $24 \mathrm{~h}$ of cultivation, and the migration ability of the cells was evaluated by measuring the width of the wounds.

Cell migration and invasion assays. Transwell inserts were loaded into 24 -well plates, and $200 \mu \mathrm{l}$ migration buffer $(0.1 \%$ BSA in RPMI-1640 medium) were added to the top chamber at $37^{\circ} \mathrm{C}$ for $1 \mathrm{~h}$. A total of $5 \times 10^{5}$ cells in $200 \mu 1$ migration buffer were seeded into the top chamber pre-treated with migration buffer and incubated for $18 \mathrm{~h}$. The lower chamber was supplemented with $600 \mu 1$ complete medium with $15 \%$ fetal calf serum (FCS). After an 18-h incubation, the cells on the upper side of the membranes were removed using a cotton swab and cells on the lower side were fixed in methanol and stained with $0.1 \%$ crystal violet and counted in five independent microscopic fields at x200 magnification.

The protocol for invasion assay was similar to that for cell migration assay except that Transwell chambers were coated with Matrigel.

Detection of cytoskeletal proteins. Climbing slices of 5-8F-DLC-1 and 5-8F-vector cells were prepared and washed with ice-cold PBS buffer on the following day. The cells were then fixed with ice-cold $4 \%$ paraformaldhyde for $20 \mathrm{~min}$, incubated in $0.2 \%(\mathrm{v} / \mathrm{v})$ Triton $\mathrm{X}-100$ for $20 \mathrm{~min}$ and stained with $1 \mu \mathrm{g} / \mathrm{ml}$ phalloidin-TRITC for $40 \mathrm{~min}$ at room temperature. The slices were washed with PBS three times (10 min per time) after each of the above steps. The cytoskeletal distribution was observed under a ZEISS LSM 5 confocal laser microscope (Carl Zeiss Inc., Oberkochen, Germany).

Microarray analysis. Total RNA from the 5-8F-vector and 5-8FDLC-1 cells was extracted using TRIzol (Invitrogen) according to the manufacturer's instructions. Microarray analysis was performed by CapitalBio Corp. (Beijing, P.R. China) using Human Genome U133 Plus2.0 GeneChip Arrays (Affymetrix, Sunnyvale, CA, USA) which covers $>54,000$ probe sets representing 47,000 transcripts and variants and including 38,500 human genes as previously described (13). The raw data were normalized with Robust Multichip Analysis (RMA). The differential expression of genes was detected with Significance Analysis of Microarrays (SAM). A two-fold or greater change in intensity was used as the criterion for inclusion in our filtered data set and the P-value was set $\leq 0.05$.

RT-PCR analysis. To detect the expression of $D L C-1$ in $5-8 \mathrm{~F}$ cells transfected with $D L C-1$ or the pcDNA3.1(+) vector and to confirm the microarray results, RT-PCR analysis was performed as previously described (11). Total cellular RNA was extracted using TRIzol (Invitrogen) and reverse transcribed using a Reverse Transcription kit (Fermentas, Hanover, MD, USA) according to the manufacturer's instructions. The cDNAs obtained were used as the template for amplification with Taq enzyme mixture (Fermentas). The primer sets, the length of PCR products, annealing temperature and cycles for amplification are listed in Table I. DLC-1 primers were taken from a previous study (10).

Statistical analysis. MTT assay, colony formation assay, FCM, and cell migration and invasion assay were carried out in triplicate. The data are presented as the means \pm SD and processed with SPSS for Windows 11.5 by using an independent-sample t-test. A P-value $<0.05$ was considered to indicate a statistically significant difference.

\section{Results}

Construction of eukaryotic expression vector pcDNA3.1(+)/ $D L C-1$ and establishment of NPC cell line stably expressing $D L C-1$. The recombinant vector was sequenced and the results showed that the coding sequence was correct except for a single nucleotide polymorphism (SNP) site at $+1380(\mathrm{G} \rightarrow \mathrm{A}$, V354M) (Fig. 1A). This vector was designated as pcDLC-1. Plasmid, either pcDLC-1 or pcDNA3.1(+) was transfected into 5-8F cells using FuGENE 6 and the cell lines stably expressing pcDLC-1 or pcDNA3.1(+) plasmids were named 5-8F-DLC-1 or $5-8 \mathrm{~F}$-vector, respectively. $D L C-1$ was highly expressed in the 5-8F-DLC-1 cells while it was absent in the 5-8F-vector cells when detected by RT-PCR (Fig. 1B) and western blot analysis (Fig. 1C). Immunocytochemical detection showed that the DLC-1 protein was mainly present in the cytoplasm of the 5-8F-DLC-1 cells (Fig. 1D).

Effects of DLC-1 on the proliferation of NPC cells. We analyzed changes in the biological characteristics of 5-8F-DLC-1 cells. Compared with the 5-8F-vector cells, the 5-8F-DLC-1 cells showed significant growth inhibition $(\mathrm{P}<0.05$, Fig. 2A) and a reduction in cloning efficiency as measured by MTT analysis and colony formation assay (23.1 vs. 52.5\%, respectively) (Fig. 2C). FCM showed that the 5-8F-DLC-1 cells were arrested at the G0/G1 phase (Fig. 2B). Compared to the $5-8$ F-vector cells, the ratio of 5-8F-DLC-1 cells at the G0/ G1 phase increased (67.25 vs. $45.39 \%$ ), while the ratio of cells 
Table I. Primers for RT-PCR analysis.

\begin{tabular}{|c|c|c|c|c|}
\hline Gene symbol & Primers $\left(5^{\prime} \rightarrow 3^{\prime}\right)$ & Product (bp) & $\begin{array}{c}\text { Annealing } \\
\text { temperature }\left({ }^{\circ} \mathrm{C}\right)\end{array}$ & Cycles (N) \\
\hline GAPDH & $\begin{array}{l}\text { F: GAGATCCCTCCAAAATCAAGTG } \\
\text { R: GAGTCCTTCCACGATACCAAAG }\end{array}$ & 282 & 58 & 30 \\
\hline$D L C-1$ & $\begin{array}{l}\text { F: GGACACCATGATCCTAACAC } \\
\text { R: CTCATCCTCGTCTGAATCGT }\end{array}$ & 262 & 55 & 35 \\
\hline WNT5A & $\begin{array}{l}\text { F: ATTCTTGGTGGTCGCTAGGTA } \\
\text { R: CGCCTTCTCCGATGTACTGC }\end{array}$ & 159 & 52 & 28 \\
\hline TNS1 & $\begin{array}{l}\text { F: GCGGGCTAAAGTGAAGTT } \\
\text { R: GGATGATGGAGTGCTGGTA }\end{array}$ & 335 & 58 & 31 \\
\hline FHL1 & $\begin{array}{l}\text { F: GACATCTGCTCTCGGTTATT } \\
\text { R: TAGTGGCAGTCAAACTTCTC }\end{array}$ & 207 & 60 & 31 \\
\hline S100A2 & $\begin{array}{l}\text { F: AAGAGGGCGACAAGTTCA } \\
\text { R: AGAGTTCTGCTTCAGGGTC }\end{array}$ & 244 & 62 & 31 \\
\hline$R E C K$ & $\begin{array}{l}\text { F: GTCTTGTATTGTTGGAGGAA } \\
\text { R: ACTGATGGTCTTGGAGGC }\end{array}$ & 260 & 58 & 34 \\
\hline DUSP2 & $\begin{array}{l}\text { F: CTGTGGAGATCTTGCCCTA } \\
\text { R: CACCCAGTCAATGAAGCCTA }\end{array}$ & 221 & 58 & 32 \\
\hline CASP9 & $\begin{array}{l}\text { F: TGCGTGGTGGTCATTC } \\
\text { R: TGGTCTTTCTGCTCCC }\end{array}$ & 194 & 60 & 30 \\
\hline IGFBP7 & $\begin{array}{l}\text { F: AACAAGGTAAAAAGGGGTCA } \\
\text { R: TGGCTGTGAGATTTATTGTGTA }\end{array}$ & 273 & 62 & 30 \\
\hline$E G F R$ & $\begin{array}{l}\text { F: GAAGGCTGTCCAACGAAT } \\
\text { R: CAGAGTCCCTTATACACCGT }\end{array}$ & 293 & 60 & 30 \\
\hline$C D C P 1$ & $\begin{array}{l}\text { F: TGACTTGAGTAATGAGCGAG } \\
\text { R: CTGTGCAGCTTATGGTTTTT }\end{array}$ & 215 & 60 & 30 \\
\hline$K R A S$ & $\begin{array}{l}\text { F: GCAAAGACAAGACAGGGTG } \\
\text { R: GGTAAAAGCTAACAGTCTGC }\end{array}$ & 264 & 60 & 30 \\
\hline$T G F \beta 2$ & $\begin{array}{l}\text { F: CCATCCCGCCCACTTTCTAC } \\
\text { R: AGCTCAATCCGTTGTTCAGGC }\end{array}$ & 195 & 60 & 30 \\
\hline$A K T 3$ & $\begin{array}{l}\text { F: AGAGAATCCAAACCCTAAAGCTGA } \\
\text { R: ATCCTATGAATGAGCCATCTGT }\end{array}$ & 185 & 60 & 30 \\
\hline$M M P 7$ & $\begin{array}{l}\text { F: GAACAGGCTCAGGACTATCT } \\
\text { R: GATCCACTGTAATATGCGGT }\end{array}$ & 283 & 60 & 32 \\
\hline MUC4 & $\begin{array}{l}\text { F: CGTTCTGGGACGATGCTGAC } \\
\text { R: GATGGCTTGGTAGGTGTTGCT }\end{array}$ & 230 & 60 & 32 \\
\hline BCL10 & $\begin{array}{l}\text { F: GTGAAGAAGGACGCCTTAGAAA } \\
\text { R: TCAACAAGGGTGTCCAGACCT }\end{array}$ & 206 & 60 & 32 \\
\hline РTK6 & $\begin{array}{l}\text { F: TGCCCCATTGGGATGACTG } \\
\text { R: GTACAGCGCCAGGATGTGTTT }\end{array}$ & 221 & 60 & 32 \\
\hline
\end{tabular}

at the $\mathrm{S}$ phase (21.24 vs. $31.26 \%$ ) and the G2/M phase (11.51 vs. $23.35 \%$ ) decreased significantly. In vivo tumorigenicity analysis confirmed that the size of the tumors formed by $5-8$ F-DLC-1 cells in nude mice was much smaller than that of the tumors formed by $5-8 \mathrm{~F}$-vector cells $(\mathrm{P}<0.05$, Fig. 2D). These results indicated that the stable expression of $D L C-1$ blocked $5-8 \mathrm{~F}$ cells at the G0/G1 phase and resulted in attenuated proliferation and colony formation ability in vitro and a lower tumorigenicity potential in vivo.
Effects of DLC-1 on cell migration and invasion of NPC cells. To determine whether $D L C-1$ affects the motility of NPC cells, in vitro wound healing assay, migration assay and invasion assay were performed. Compared with the 5-8F-vector cells, the 5-8F-DLC-1 cells closed the wound more slowly (Fig. 3A) and the number of cells penetrating the Transwell membrane was significantly lower $(18 \pm 4.0$ vs. $42 \pm 5.6 ; \mathrm{P}<0.00)$ (Fig. $3 \mathrm{~B})$, indicating that the motility of DLC-1-expressing cells was significantly impaired. When observed after a 24 h-cultivation, 
A

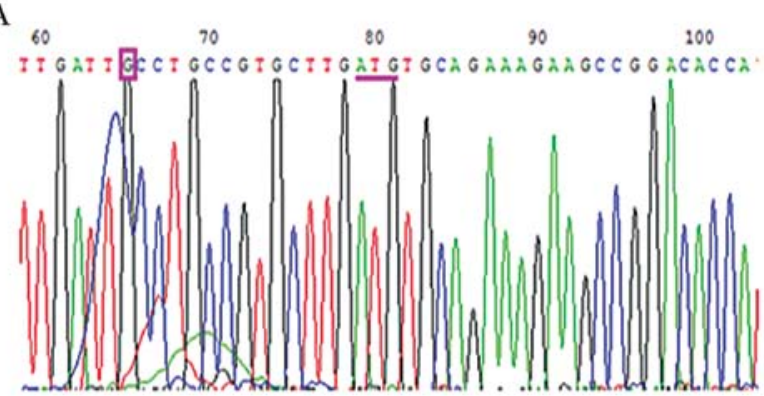

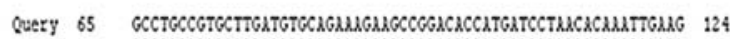

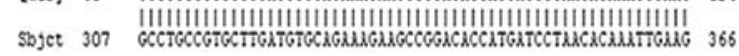

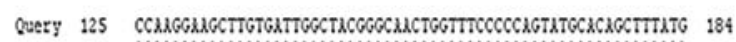

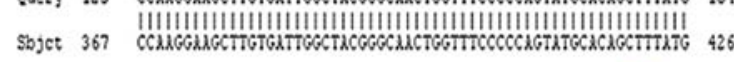

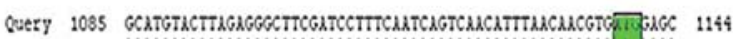

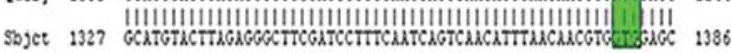

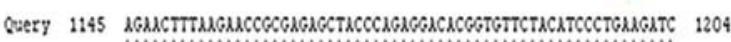

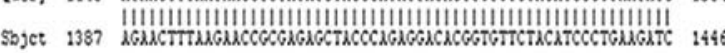

B

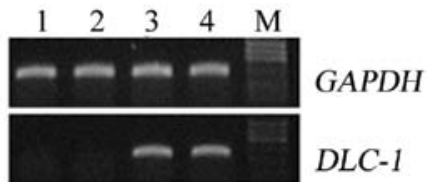

C

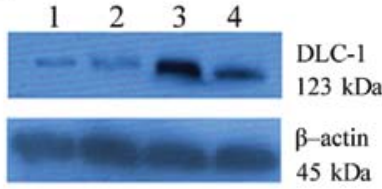

$\mathrm{D}$

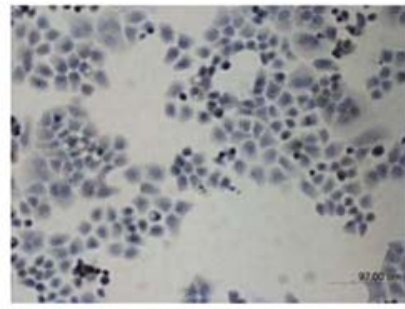

$5-8 \mathrm{~F}-\mathrm{vector}$

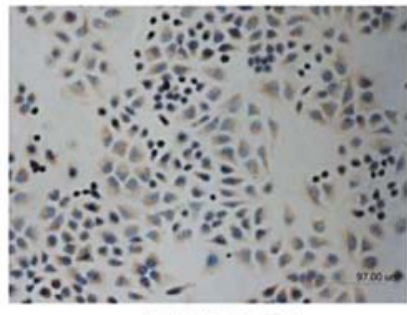

$5-8$ F-DLC- -1

Figure 1. Construction of eukaryotic $D L C-1$ expression vector and establishment of 5-8F-DLC-1 cells. (A) BLAST analysis of cloned $D L C-1$ ORF sequence. Green frame shows an $\mathrm{A} \rightarrow \mathrm{G}$ SNP at +1380 . (B and C) Detection of $D L C-1$ expression by RT-PCR and western blot analysis, respectively. Lanes 1 and 2 represent DLC-1 expression in 5-8F-vector cells. Lanes 3 and 4 represent that in 5-8F-DLC-1 cells. GAPDH and $\beta$-actin was used as an internal control, respectively. (D) Immunostaining showed that DLC-1 protein was mainly present in the cytoplasm in the 5-8F-DLC-1 cells, but not in the 5-8F-vector cells (DAB, x200).
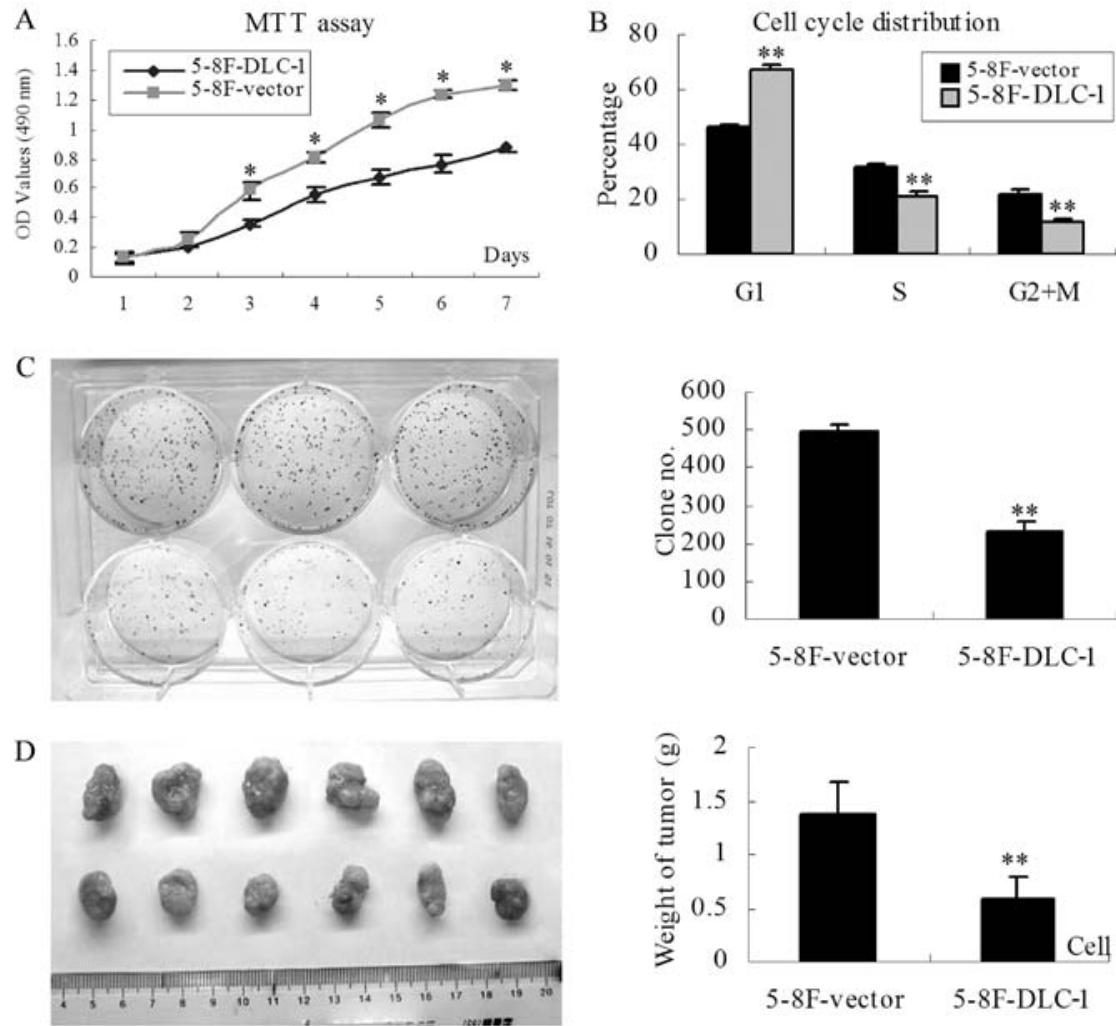

Figure 2. Effects of DLC-1 on biological function of 5-8F cells. (A) MTT assay showed that compared with that of the 5-8F-vector cells, the growth of the 5-8F-DLC-1 cells was inhibited. (B) Cell cycle distribution of 5-8F-DLC-1 cells and 5-8F-vector cells analyzed by flow cytometry. (C) Colony formation assay of 5-8F-vector cells (left panel, top lane) and 5-8F-DLC-1 cells (left panel, bottom lane) and bar chart of the assay data (right panel). (D) Tumor blocks formed by the inoculation of 5-8F-vector cells (left panel, top lane) and 5-8F-DLC-1 cells (left panel, bottom lane) into nude mice. A bar chart of the weight data of the tumor blocks is shown in the right panel. Error bars represent the means \pm SD from three independent experiments. ${ }^{* *} \mathrm{P}<0.05$. 
A

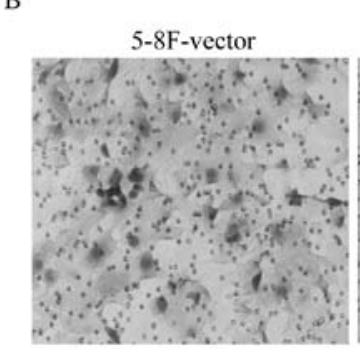

C

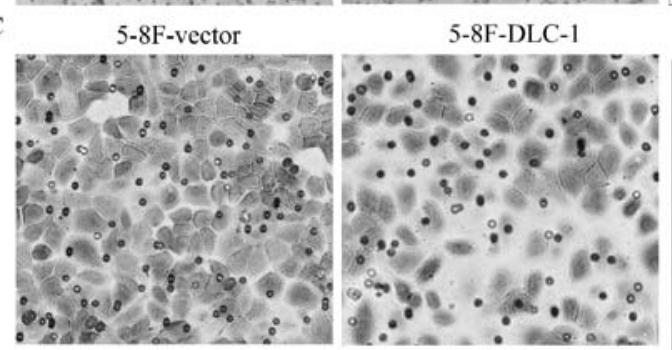

5-8F-vector

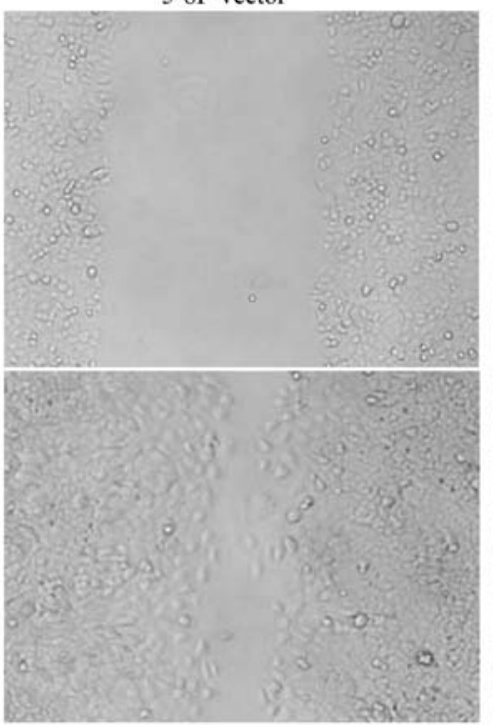

$5-8$ F-DLC-1

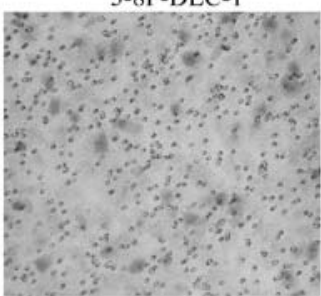

$5-8$ F-DLC-1
5-8F-DLC-1
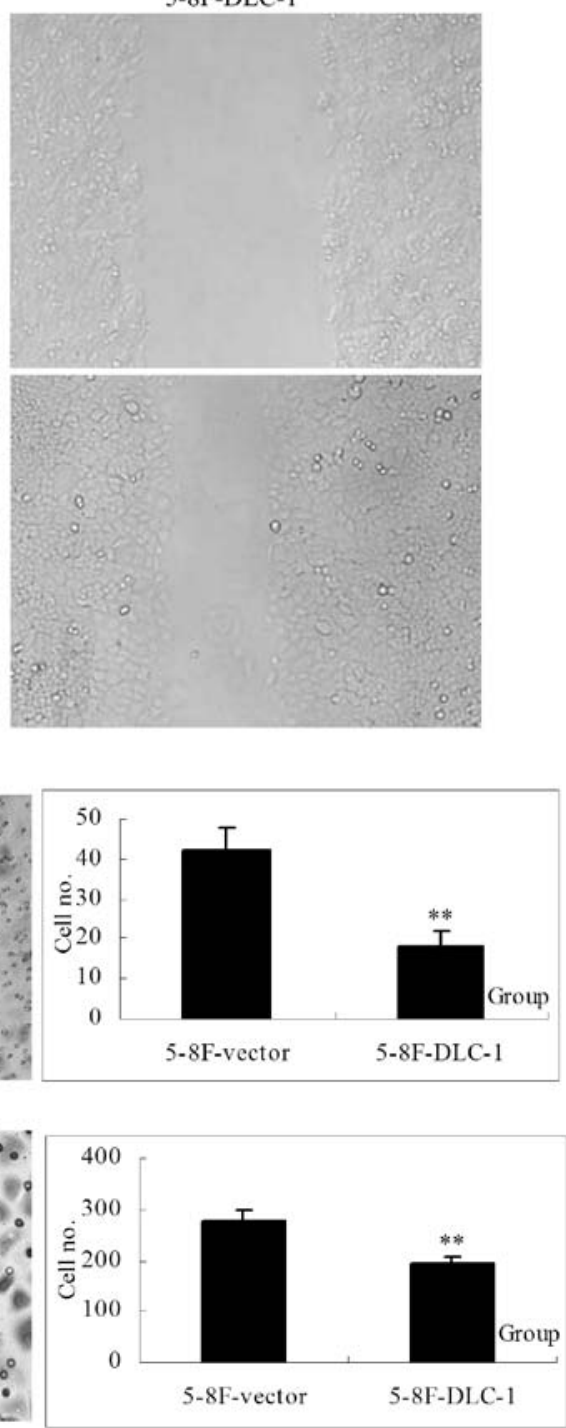

Figure 3. Effects of $D L C-1$ on the motility of 5-8F cells. (A) Wound healing assay, (B) migration assay and (C) invasion assay of 5-8F-vector cells (left panel) and 5-8F-DLC-1 cells (right panel). Bar charts show analysis of the number of cells penetrating the Transwell membrane. Error bars represent the means \pm SD from three independent experiments. (B) ${ }^{* * *} \mathrm{P}<0.00$ and $(\mathrm{C}){ }^{* *} \mathrm{P}<0.05$.

the number of 5-8F-DLC-1 and 5-8F-vector cells penetrating the Transwell membrane coated with Matrigel was $191.40 \pm 16.6$ and $278 \pm 20.7$, respectively $(\mathrm{n}=5, \mathrm{P}<0.05)$ (Fig. 3C), indicating a significant reduction in the invasive ability of 5-8F-DLC-1 cells.

Effect of DLC-1 on cytoskeletal formation. Phalloidin is a virulent alkaloid extracted from a toxic mushroom and can solidly bind with the cell membrane and fibrous actin (F-actin). Fluorescently-labeled phalloidin was used to specifically mark cell surface morphology and changes in F-actin distribution. In the 5-8F-vector cells, abundant F-actin was observed at the cell periphery, a prominent site of the cytoplasm, and throughout the cytoplasm (Fig. 4); while in the 5-8F-DLC-1 cells, microfilaments exhibited polar and circular distribution, focused along the cell periphery and were significantly decreased in the cytoplasm as compared with those in the $5-8 \mathrm{~F}$-vector cells (Fig. 4). This is an indication that $D L C$ - 1 plays a crucial role in cytoskeletal formation, which may be one of the mechanisms behind its effect on NPC cell motility.
DLC-1 expression induces differential expression of certain tumor-related genes in NPC cells. To investigate the molecular mechanism behind the inhibitory effect of $D L C-1$ expression on the biological characteristics of tumor cells, microarray analysis was performed to compare gene expression profiles in $5-8 \mathrm{~F}$-vector and 5-8F-DLC-1 cell groups. The gene expression levels were compared between the two groups. The expression of 840 genes and 151 expressed sequence tags (ESTs) was significantly altered in the 5-8F-DLC-1 group as compared to that in the 5-8F-vector group. Among these genes, 454 were upregulated and 386 were downregulated. The most differentially expressed or altered critical tumor-related genes are listed in Tables II and III. As shown in Table II, genes that act as tumor suppressors, such as IGFBP7, TNS1, TP53 and TP63, were significantly upregulated by the $D L C-1$ gene. Those acting as oncogenes, such as $E G F R, K R A S$ and $T G F \beta 2$, were significantly downregulated (Table III).

To validate our array expression findings, 17 of the differentially expressed genes, such as WNT5A, TNS1, FHL1, 
Table II. Representative upregulated genes induced by $D L C-1$ gene expression in the 5-8F cell line.

\begin{tabular}{|c|c|c|c|}
\hline Gene symbol & Description & RefSeq & $\begin{array}{c}\text { Fold change } \\
\text { (DLC-1 vs. vector) }\end{array}$ \\
\hline CASP9 & Caspase 9, apoptosis-related cysteine peptidase & NM_032996 & 5.00 \\
\hline DUSP2 & Dual specificity phosphatase 2 & NM_004418 & 24.97 \\
\hline FHL1 & Four and a half LIM domains 1 & NM_001449 & 2.65 \\
\hline GAS1 & Growth arrest-specific 1 & NM_002048 & 6.15 \\
\hline$H D A C 4$ & Histone deacetylase 4 & NM_006037 & 7.59 \\
\hline$I G F B P 7$ & Insulin-like growth factor binding protein 7 & NM_001553 & 3.09 \\
\hline$P D C D 4$ & Programmed cell death 4 (neoplastic transformation inhibitor) & NM_014456 & 2.93 \\
\hline RASSF6 & Ras association (RalGDS/AF-6) domain family member 6 & NM_177532 & 5.09 \\
\hline$R E C K$ & Reversion-inducing-cysteine-rich protein with kazal motifs & NM_021111 & 2.67 \\
\hline$S 100 A 2$ & S100 calcium binding protein A2 & NM_005978 & 3.00 \\
\hline TANK & TRAF family member-associated NF- $\kappa \mathrm{B}$ activator & NM_004180 & 2.03 \\
\hline$T L N 2$ & Talin 2 & NM_015059 & 3.31 \\
\hline TNS1 & Tensin 1 & NM_022648 & 2.89 \\
\hline TP53TG1 & TP53 target 1 (non-protein coding) & NR_015381 & 3.60 \\
\hline TP63 & Tumor protein $\mathrm{p} 63$ & NM_001114980 & 2.98 \\
\hline VWA5A & Von Willebrand factor A domain containing $5 \mathrm{~A}$ & NM_198315 & 7.60 \\
\hline WNT5A & Wingless-type MMTV integration site family, member 5A & NM_003392 & 4.99 \\
\hline$W W O X$ & WW domain containing oxidoreductase & NM_016373 & 3.40 \\
\hline
\end{tabular}

RefSeq, reference sequence.

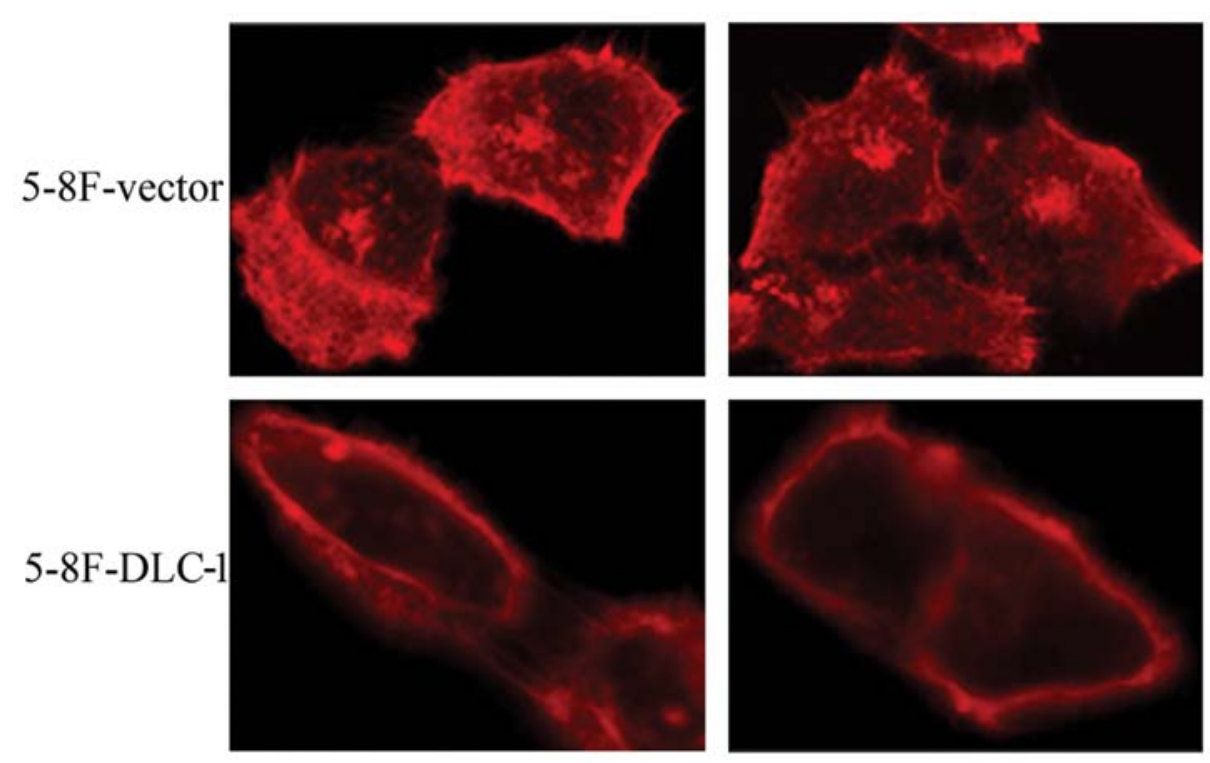

Figure 4. Detection of F-actin distribution with phalloidin staining. Cells were plated onto polylysine-coated coverslips. After $24 \mathrm{~h}$ of cultivation, the cells were stained with fluorescent phalloidin. Images were acquired with a laser scanning confocal microscope.

S100A2, RECK, DUSP2, CASP9, IGFBP7, EGFR, CDCP1, KRAS, TGFß2, AKT3, MMP7, MUC4, BCL10 and PTK6 were selected for further verification with RT-PCR analysis. As shown in Fig. 5, eight of these genes, namely WNT5A, TNS1, FHL1, S100A2, RECK, DUSP2, CASP9 and IGFBP7 were found to be upregulated, while nine genes, including EGFR, CDCP1, KRAS, TGF 2 2, AKT3, MMP7, MUC4, BCL10 and PTK6 were downregulated in the 5-8F-DLC-1 cells as compared to the control 5-8F-vector cells. The trends for either the up- or downregulation of mRNA expression obtained by RT-PCR were consistent with the microarray results.

Furthermore, using Gene Ontology (GO) and Kyoto Encyclopedia of Genes and Genomes (KEGG) software, we analyzed the microarray dataset to identify whether specific 
Table III. Representative downregulated genes induced by $D L C-1$ gene expression in the $5-8 \mathrm{~F}$ cell line.

\begin{tabular}{|c|c|c|c|}
\hline $\begin{array}{l}\text { Gene } \\
\text { symbol }\end{array}$ & Description & RefSeq & $\begin{array}{c}\text { Fold change } \\
\text { (DLC-1 vs. vector) }\end{array}$ \\
\hline AKT3 & V-akt murine thymoma viral oncogene homolog 3 (protein kinase $B, \gamma)$ & NM_005465 & 0.52 \\
\hline BCL10 & B-cell CLL/lymphoma 10 & NM_003921 & 0.44 \\
\hline CD44 & CD44 molecule (Indian blood group) & NM_000610 & 0.23 \\
\hline$C D C P 1$ & CUB domain containing protein 1 & NM_022842 & 0.37 \\
\hline$E G F R$ & $\begin{array}{l}\text { Epidermal growth factor receptor [erythroblastic leukemia viral (v-erb-b) } \\
\text { oncogene homolog, avian] }\end{array}$ & NM_005228 & 0.50 \\
\hline ETS1 & v-ets erythroblastosis virus E26 oncogene homolog 1 (avian) & NM_005238 & 0.45 \\
\hline$F G F 2$ & Fibroblast growth factor 2 (basic) & NM_002006 & 0.46 \\
\hline FOSL1 & FOS-like antigen 1 & NM_005438 & 0.35 \\
\hline KRAS & v-Ki-ras2 Kirsten rat sarcoma viral oncogene homolog & NM_033360 & 0.23 \\
\hline$L A M C 2$ & Laminin, $\gamma 2$ & NM_144652 & 0.14 \\
\hline$M M P 7$ & Matrix metallopeptidase 7 (matrilysin, uterine) & NM_002423 & 0.15 \\
\hline MUC4 & Mucin 4, cell surface associated & NM_018406 & 0.33 \\
\hline$N E X N$ & Nexilin (F-actin binding protein) & NM_144573 & 0.22 \\
\hline PCSK6 & Proprotein convertase subtilisin/kexin type 6 & NM_002570 & 0.37 \\
\hline PTK6 & PTK6 protein tyrosine kinase 6 & NM_005975 & 0.48 \\
\hline STYK1 & Serine/threonine/tyrosine kinase 1 & NM_018423 & 0.48 \\
\hline ST14 & Suppression of tumorigenicity 14 (colon carcinoma) & NM_021978 & 0.38 \\
\hline$T G F \beta 2$ & Transforming growth factor, $\beta 2$ & NM_001135599 & 0.36 \\
\hline WIPF1 & WAS/WASL interacting protein family, member 1 & NM_003387 & 0.37 \\
\hline
\end{tabular}

RefSeq, reference sequence.

A

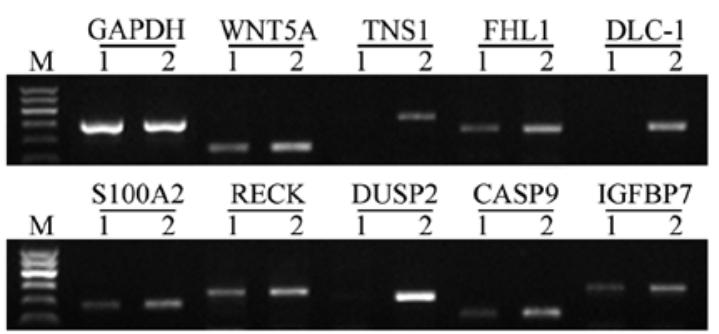

B

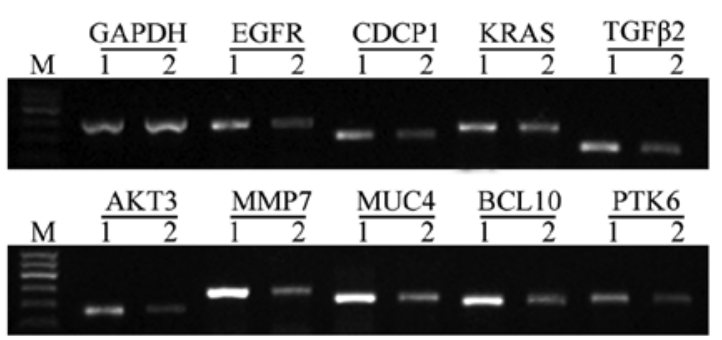

Figure 5. RT-PCR identification of differential gene expression affected by DLC- 1 expression in NPC $5-8 \mathrm{~F}$ cells. To validate the results of microarray analysis, 17 differentially expressed genes in response to $D L C-1$ expression in 5-8F cells were selected for RT-PCR verification. (A) RT-PCR detected the expression levels of eight upregulated genes in $5-8 \mathrm{~F}$ cells stably overexpressing $D L C-1$ and the control $5-8 \mathrm{~F}$ cells transfected with the empty vector. (B) RT-PCR detected the expression levels of nine downregulated genes in the $5-8 \mathrm{~F}$ cells stably overexpressing DLC-1 and the control $5-8 \mathrm{~F}$ cells transfected with the empty vector. Lanes 1 and 2 represent amplification using reverse transcripts derived from the control 5-8F-vectors and 5-8F-DLC-1 cells, respectively. biological pathways were differentially affected by the $D L C-1$ gene. As shown in Fig. 6, proteins encoded by these genes were mainly observed in the cytoplasm and nucleus. Their molecular functions include protein binding, metal ion binding and nucleotide binding and they participate in some important biological process mainly associated with cell adhesion, negative regulation of cell proliferation, cell cycle arrest and the inhibition of apoptosis. Pathway analysis indicated that the altered genes were associated with a number of essential biological processes, such as tumor-related pathways including focal adhesion, MAPK signaling, VEGF and TGF $\beta$ signaling and apoptotic pathways along with several specific cancerrelated and metabolism-related pathways (Fig. 7).

\section{Discussion}

The $D L C-1$ gene is considered an important TSG candidate (5). It is located at chromosome $8 \mathrm{p} 22$, a region that exhibits high loss frequency in NPC tissues and is closely associated with NPC (10). In order to further investigate the biological function of $D L C-1$ in NPC, we transfected the constructed pcDLC-1 plasmid, a $D L C$ - 1 eukaryotic expression vector, into 5-8F NPC cells and established a cell line (5-8F-DLC-1) stably expressing $D L C-1.5-8 \mathrm{~F}$ is a highly tumorigenic, highly metastatic NPC cell line and a good model for studying the invasive and metastatic mechanisms of NPC (14). Although there was a missense 
GO:0006355 regulation of transcription, DNA-dependent $4.8 \%$

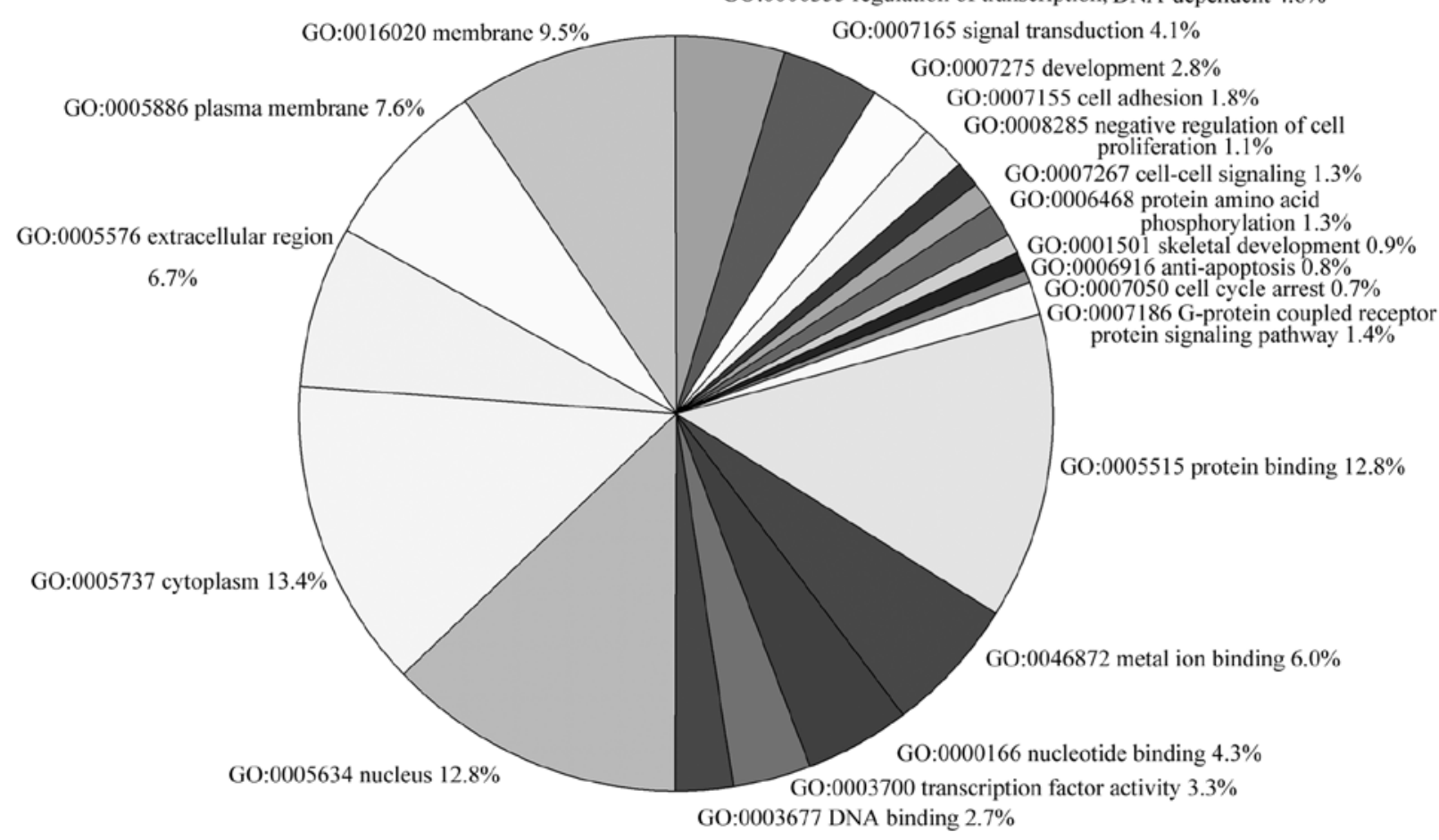

Figure 6. Representative molecular functions of differentially expressed genes affected by $D L C-1$.

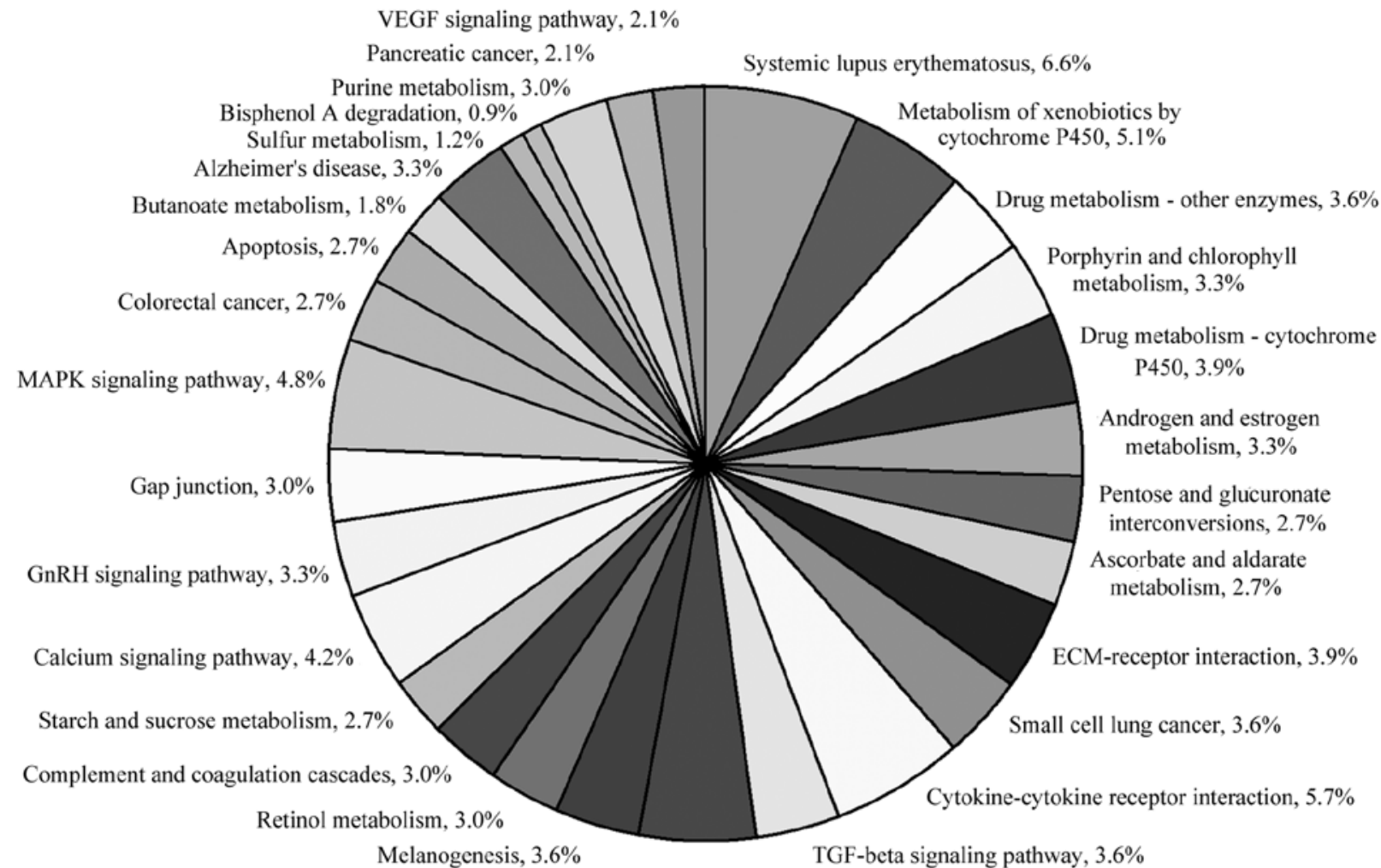

Focal adhesion, $5.1 \%$

Figure 7. Representative altered signaling pathways associated with differentially expressed genes affected by $D L C-1$.

SNP site in the obtained ORF sequence, bioinformatics analysis and literature investigation indicated that this site was not in any of the known important domains. Furthermore, secondary structure prediction did not reveal any obvious changes and there was no report about any effects of this SNP on protein function. Therefore, we continued to use the 5-8F-DLC-1 cell 
line to investigate changes in the biological characteristics of NPC cells induced by the re-expression of $D L C-1$.

NPC is a malignancy with predisposition to early metastasis. It is often at the middle or advanced stage at clinical examination. Studies have shown that recovering the expression of $D L C-1$ in hepatic carcinoma $(15,16)$, breast cancer $(17)$, nonsmall cell lung cancer (NSCLC) (18) and multiple myeloma cells (19) results in the reduction of cytoskeletal content, alteration of cell morphology and the inhibition of tumor growth and metastasis. Seng et al reported that $D L C-1$ suppresses the colony formation of CNE2 NPC cells (10) and Loyo et al showed that $D L C-1$ decreases the growth and invasion capacity in a human nasal epithelial (HNE) cell line (20). Our results indicated that $D L C-1$ not only suppressed cell growth and proliferation, but also inhibited the motility, migration and invasion ability of 5-8F cells. Compared with those in 5-8F-vector cells, the microfilaments were reduced and exhibited circular/ polar distribution around the cell membrane in the 5-8F-DLC-1 cells, as observed in multiple myeloma cells (19). Therefore, our results further suggest that $D L C$ - 1 plays an important role in the tumorigenesis and metastasis of NPC.

$D L C-1$ is the earliest cloned member of the $D L C$ gene family, which consists of the RhoGAP, START and SAM domains and unstructured middle regions, such as the serine-rich region, tensin-binding motif (SIYDNV) and LD motif (LDDILYHV) $(7,21,22)$. DLC-1 is a GTPase-activating protein (GAP) and inhibits tumor growth and progression through the activation of intrinsic GTPase of Rho family proteins by the RhoGAP domain, which subsequently results in the inactivation of Rho protein. However, some studies have reported that DLC-1 participates in suppressing tumor growth and metastasis by binding with the SH2 domain of tensin through 440-445 amino acid residues (SIYDNV) and the inhibition of Rho protein activity through RhoGAP domain was not required $(23,24)$. In addition, DLC-1 has been reported to bind talin protein through its LD motif and perform its function. Thus far, there is no report on the specific mechanisms underlying the tumor suppressive function of $D L C-1$ in NPC. Whether it functions through the inhibition of certain Rho protein activity, binding with tensins or other mechanisms remains to be elucidated.

Using Affymetrix Human Genome U133 Plus2.0 GeneChip Array, we found that $D L C-1$ affected the expression of a series of genes. Most of the upregulated genes exhibited tumor suppressor characteristics. For example, tensin 1 (TNS1) is a protein localized at focal adhesions acting as a scaffold for the signaling pathway. Furthermore, the SH2 domain of TNS1 is associated with DLC-1. Human breast, prostate and head and neck squamous cell carcinoma, as well as melanoma exhibit low expression levels of TNS1, suggesting that it functions as a tumor suppressor. The re-expression of TNS1 has been shown to promote the formation of focal adhesions and to decrease the migration and invasion of MDA-MB-231 human breast cancer cells (25). Reversion-inducing-cysteine-rich protein with kazal motifs (RECK) is a cysteine-rich, extracellular protein with protease inhibitor-like domains whose expression is significantly suppressed in several tumors (26), including NPC (27). RECK has been reported to inhibit tumor angiogenesis, invasion and metastasis by negatively regulating matrix metalloproteinases (MMPs) (28). Dual specificity phosphatase 2 (DUSP2), originally named phosphatase of activated cells-1 (PAC-1), is a member of the dual specificity protein phosphatase subfamily and predominantly inactivates ERK, but also inactivates p38 MAPK, although to a lesser degree $(29,30)$. DUSP2 mRNA and protein are markedly reduced or completely absent in many types of cancer. The re-expression of DUSP 2 in xenograft mouse models of cancer has been reported to increase drug sensitivity and induce tumor regression (31).

By contrast, some of the downregulated genes exhibit oncogenic characteristics. Epidermal growth factor receptor (EGFR) is one of the most widely known receptor tyrosine kinases. The overexpression of EGFR is common in NPC and most NPC cell lines and approximately $85 \%$ of Chinese NPC patients have a moderate to strong expression of EGFR. Moreover, the overexpression of $E G F R$ in primary tumors is associated with tumor metastasis, recurrence and a low survival rate in patients with NPC, suggesting that EGFR plays a crucial role in the development and progression of NPC (32). The role of TGF $\beta$ in tumorigenesis is complex. In different cell types and stages, TGF $\beta$ has either positive or negative effects. High levels of TGF $\beta 2$ have been observed in many tumor cell lines, which promotes the survival of tumor cells by activating nuclear factor- $\kappa \mathrm{B}(\mathrm{NF}-\kappa \mathrm{B})(33)$. Additionally, MMP7, a member of the MMP family, is overexpressed in a variety of epithelial and mesenchymal tumors and its expression correlates with tumor progression, metastasis and unfavorable prognosis in human esophageal, colon and gastric carcinoma (34-36). CUB domain containing protein 1 (CDCP1), a type I transmembrane protein containing three extracellular CUB domains, has been found to be overexpressed in many types of cancer and its overexpression is significantly associated with poor prognosis in relation to disease-free and overall survival $(37,38)$. The downregulation of $C D C P 1$ by RNA interference in lung and gastric carcinoma cells has been shown to result in suppressed invasion and experimental metastasis $(38,39)$. Our array results suggested that $D L C-1$ suppressed NPC cell growth and metastasis through the upregulation of tumor suppressors and the downregulation of oncogenes or metastasis-related genes.

A variety of aberrantly altered signals is an important factor mediating the biological behavior of NPC including carcinogenesis and development. Such signaling pathways are critical for cell survival, growth and metastasis. A number of studies have shown that Wnt, PI3K-Akt, MAPK, focal adhesion, apoptosis and EGRF signaling pathways contribute to the tumorigenesis of NPC $(40,41)$. Using KEGG software, we also found that focal adhesion, MAPK, VEGF and apoptosis signaling pathways, etc., were altered in 5-8F-DLC-1 cells, suggesting that $D L C-1$ performed its biological function including suppressing cell growth and metastasis in NPC by regulating such tumor-related pathways. In addition, many altered metabolism associated pathways were be found in this study, suggesting that metabolic regulation play an important role in inhibitory effects of $D L C-1$ on NPC cells. An everincreasing amount of evidence demonstrates that metabolism is another important factor contributing to carcinogenesis and tumor development (42). The role of $D L C-1$ as a tumor suppressor and its effects on metabolism in NPC remain to be further elucidated.

In conclusion, our results demonstrate that $D L C-1$ partially alters the malignant phenotypes of NPC cells, which includes the inhibition of cell proliferation and the suppression of inva- 
sion and metastasis etc., through the regulation of the expression of tumor suppressors, oncogenes or metastasis-related genes and affecting cancer-related pathways. This study provides a theoretical and experimental basis for comprehensively understanding the biological function of the $D L C-1$ gene in NPC and further elucidating the molecular mechanisms of NPC carcinogenesis. Our data open up a new avenue for the more effective diagnosis and treatment of NPC.

\section{Acknowledgments}

This study was supported by grants from the National Basic Research Program of China (2010CB833605), the Program for New Century Excellent Talents in University (NCET-10-0790), the National Natural Science Foundation of China (30801322, 81172206,81272972), the Provincial Natural Science Foundation of Hunan (10JJ4025), Science and Technology Project of Hunan Province (2010FJ3005), the Incubation Program for National Natural Science Funds for Distinguished Young Scholar of Central South University (2010QYZD006), and the Open-End Fund for the Valuable and Precision Instruments of Central South University (CSUZC2012009, CSUZC2012010).

\section{References}

1. Chang ET and Adami HO: The enigmatic epidemiology of nasopharyngeal carcinoma. Cancer Epidemiol Biomarkers Prev 15: 1765-1777, 2006

2. Yao KT: The application and prospect of nasopharyngeal carcinoma etiology. China Cancer 6: 3-4, 1997.

3. Lo KW, To KF and Huang DP: Focus on nasopharyngeal carcinoma. Cancer Cell 5: 423-428, 2004.

4. Wei WI and Sham JS: Nasopharyngeal carcinoma. Lancet 365: 2041-2054, 2005.

5. Tao Q and Chan AT: Nasopharyngeal carcinoma: molecular pathogenesis and therapeutic developments. Expert Rev Mol Med 9: 1-24, 2007

6. Yuan BZ, Miller MJ, Keck CL, Zimonjic DB, Thorgeirsson SS and Popescu NC: Cloning, characterization, and chromosomal localization of a gene frequently deleted in human liver cancer (DLC-1) homologous to rat RhoGAP. Cancer Res 58: 2196-2199, 1998.

7. Durkin ME, Yuan BZ, Zhou X, et al: DLC-1: a Rho GTPaseactivating protein and tumour suppressor. J Cell Mol Med 11: $1185-1207,2007$

8. Lahoz A and Hall A: DLC-1: a significant GAP in the cancer genome. Genes Dev 22: 1724-1730, 2008.

9. Peng D, Ren CP, Yi HM, et al: Genetic and epigenetic alterations of DLC-1, a candidate tumor suppressor gene, in nasopharyngeal carcinoma. Acta Biochim Biophys Sin (Shanghai) 38: 349-355, 2006.

10. Seng TJ, Low JS, Li H, et al: The major 8p22 tumor suppressor DLC1 is frequently silenced by methylation in both endemic and sporadic nasopharyngeal, esophageal, and cervical carcinomas, and inhibits tumor cell colony formation. Oncogene 26: 934-944, 2007.

11. Zhang H, Feng X, Liu W, et al: Underlying mechanisms for LTF inactivation and its functional analysis in nasopharyngeal carcinoma cell lines. J Cell Biochem 112: 1832-1843, 2011.

12. Zhou W, Feng X, Li H, et al: Functional evidence for a nasopharyngeal carcinoma-related gene BCAT1 located at 12p12. Oncol Res 16: 405-413, 2007.

13. Shao JY, Wang HY, Huang XM, et al: Genome-wide allelotype analysis of sporadic primary nasopharyngeal carcinoma from southern China. Int J Oncol 17: 1267-1275, 2000.

14. Song L and Wang H: Study on the tumor heterogeneity of nasopharyngeal carcinoma cell line (SUNE-1). Chin J Cancer 17: 324-327, 1998

15. Kim TY, Lee JW, Kim HP, et al: DLC-1, a GTPase-activating protein for Rho, is associated with cell proliferation, morphology, and migration in human hepatocellular carcinoma. Biochem Biophys Res Commun 355: 72-77, 2007.
16. Wong CM, Yam JW, Ching YP, et al: Rho GTPase-activating protein deleted in liver cancer suppresses cell proliferation and invasion in hepatocellular carcinoma. Cancer Res 65: 8861-8868, 2005.

17. Goodison S, Yuan J, Sloan D, et al: The RhoGAP protein DLC-1 functions as a metastasis suppressor in breast cancer cells. Cancer Res 65: 6042-6053, 2005.

18. Yuan BZ, Jefferson AM, Millecchia L, Popescu NC and Reynolds SH: Morphological changes and nuclear translocation of DLC1 tumor suppressor protein precede apoptosis in human non-small cell lung carcinoma cells. Exp Cell Res 313: 3868-3880, 2007.

19. Ullmannova-Benson V, Guan M, Zhou X, et al: DLC1 tumor suppressor gene inhibits migration and invasion of multiple myeloma cells through RhoA GTPase pathway. Leukemia 23: 383-390, 2009.

20. Loyo M, Brait M, Kim MS, et al: A survey of methylated candidate tumor suppressor genes in nasopharyngeal carcinoma. Int J Cancer 128: 1393-1403, 2011.

21. Li G, Du X, Vass WC, Papageorge AG, Lowy DR and Qian X: Full activity of the deleted in liver cancer 1 (DLC1) tumor suppressor depends on an LD-like motif that binds talin and focal adhesion kinase (FAK). Proc Natl Acad Sci USA 108: 17129-17134, 2011

22. Qian X, Li G, Asmussen HK, et al: Oncogenic inhibition by a deleted in liver cancer gene requires cooperation between tensin binding and Rho-specific GTPase-activating protein activities. Proc Natl Acad Sci USA 104: 9012-9017, 2007.

23. Liao YC, Si L, deVere White RW and Lo SH: The phosphotyrosine-independent interaction of DLC-1 and the SH2 domain of cten regulates focal adhesion localization and growth suppression activity of DLC-1. J Cell Biol 176: 43-49, 2007.

24. Yam JW, Ko FC, Chan CY, Jin DY and Ng IO: Interaction of deleted in liver cancer 1 with tensin 2 in caveolae and implications in tumor suppression. Cancer Res 66: 8367-8372, 2006.

25. Hall EH, Balsbaugh JL, Rose KL, Shabanowitz J, Hunt DF and Brautigan DL: Comprehensive analysis of phosphorylation sites in Tensin1 reveals regulation by p38MAPK. Mol Cell Proteomics 9: 2853-2863, 2010.

26. Deng YF, Zhou DN, Ye CS, Zeng L and Yin P: Aberrant expression levels of MTA1 and RECK in nasopharyngeal carcinoma: association with metastasis, recurrence, and prognosis. Ann Otol Rhinol Laryngol 121: 457-465, 2012.

27. Meng N, Li Y, Zhang H and Sun XF: RECK, a novel matrix metalloproteinase regulator. Histol Histopathol 23: 1003-1010, 2008.

28. Noda M, Oh J, Takahashi R, Kondo S, Kitayama H and Takahashi C: RECK: a novel suppressor of malignancy linking oncogenic signaling to extracellular matrix remodeling. Cancer Metastasis Rev 22: 167-175, 2003.

29. Rohan PJ, Davis P, Moskaluk CA, et al: PAC-1: a mitogen-induced nuclear protein tyrosine phosphatase. Science 259: 1763-1766, 1993.

30. Zhang Q, Muller M, Chen CH, Zeng L, Farooq A and Zhou MM: New insights into the catalytic activation of the MAPK phosphatase PAC-1 induced by its substrate MAPK ERK2 binding. J Mol Biol 354: 777-788, 2005

31. Lin SC, Chien CW, Lee JC, et al: Suppression of dual-specificity phosphatase- 2 by hypoxia increases chemoresistance and malignancy in human cancer cells. J Clin Invest 121: 1905-1916, 2011.

32. Ruan L, Li XH, Wan XX, et al: Analysis of EGFR signaling pathway in nasopharyngeal carcinoma cells by quantitative phosphoproteomics. Proteome Sci 9: 35, 2011.

33. Wan Y, Yang M, Kolattukudy S, Stark GR and Lu T: Activation of cAMP-responsive-element-binding protein by PI3 kinase and p38 MAPK is essential for elevated expression of transforming growth factor beta2 in cancer cells. J Interferon Cytokine Res 30: 677-681, 2010.

34. Tanioka Y, Yoshida T, Yagawa T, et al: Matrix metalloproteinase-7 and matrix metalloproteinase- 9 are associated with unfavourable prognosis in superficial oesophageal cancer. Br J Cancer 89: 2116-2121, 2003.

35. Koskensalo S, Louhimo J, Nordling S, Hagstrom J and Haglund C: MMP-7 as a prognostic marker in colorectal cancer. Tumour Biol 32: 259-264, 2011.

36. Koskensalo S, Mrena J, Wiksten JP, et al: MMP-7 overexpression is an independent prognostic marker in gastric cancer. Tumour Biol 31: 149-155, 2010. 
37. Awakura Y, Nakamura E, Takahashi T, et al: Microarray-based identification of CUB-domain containing protein 1 as a potential prognostic marker in conventional renal cell carcinoma. J Cancer Res Clin Oncol 134: 1363-1369, 2008.

38. Ikeda J, Oda T, Inoue M, et al: Expression of CUB domain containing protein (CDCP1) is correlated with prognosis and survival of patients with adenocarcinoma of lung. Cancer Sci 100: 429-433, 2009

39. Uekita T, Jia L, Narisawa-Saito M, Yokota J, Kiyono T and Sakai R: CUB domain-containing protein 1 is a novel regulator of anoikis resistance in lung adenocarcinoma. Mol Cell Biol 27: 7649-7660, 2007.
40. Chou J, Lin YC, Kim J, et al: Nasopharyngeal carcinoma - review of the molecular mechanisms of tumorigenesis. Head Neck 30: 946-963, 2008

41. Tulalamba W and Janvilisri T: Nasopharyngeal carcinoma signaling pathway: an update on molecular biomarkers. Int J Cell Biol 2012: 594681, 2012.

42. Dang CV: Links between metabolism and cancer. Genes Dev 26: 877-890, 2012. 